\title{
Opioid-induced Hyperalgesia: Myth or Burgeoning Public Health CRISIS?
}

\author{
Kenneth D. Candido, MD
}

There has been considerable discussion recently regarding what, if any, role opioid-induced hyperalgesia $(\mathrm{OlH})$ plays in determining the observed phenomenon occurring in some, but not all patients chronically consuming opioids who seek escalating doses of these potent pain relievers during the course of their disease or condition. In today's climate of drastic and rapid changes in the way interventional pain management physicians view the use of prescription opioids (1-6), the use of the "OIH disclaimer" may become a rallying cry used to try to liberate patients from their beloved narcotics. It has been stated that "clinicians should suspect $\mathrm{OIH}$ when opioid treatment's effect seems to wane if the absence of disease progression, particularly if found in the context of unexplained pain reports or diffuse allodynia unassociated with the original pain, and increased levels of pain with increasing dosages" (6). This discussion has led to some insisting to patients that they "must reduce their use of opioid pain medications if they stand a chance of improving their pain, due to opioid-induced hyperalgesia."

Admittedly, despite the identification of 2,359 peer-reviewed articles and letters from a PubMed ${ }^{\circledR}$ engine search conducted on July 01, 2017 utilizing the single key phrase "opioid induced hyperalgesia", the medical community at large continues to be

Kenneth D. Candido, MD

Editor in Chief, Interventional Pain Management Reports

Chairman, Department of Anesthesia

Advocate Illinois Masonic Medical Center

Professor of Clinical Anesthesiology and Surgery

University of Illinois College of Medicine-Chicago

Address for correspondance: Department of Anesthesiology and Pain Management, Advocate Illinois Masonic Medical Center, 836 Wellington Ave., Chicago, IL 60657

E-mail: kdcandido@yahoo.com somewhat baffled by agreeing whether or not this is a condition exclusively seen in laboratory animals or whether it may be a phenomenon seen as well in humans. There continues to be debate regarding this somewhat elusive condition and its legitimacy as clinical entity requiring attention and treatment. Most studies conducted in humans revolve around rapid-acting intravenous opioids such as alfentanil (7) and remifentanil (8), in acute hyperalgesic states created experimentally (1), or else in recovering drug addicts, and have not been as precise in defining the role of $\mathrm{OlH}$ with chronic oral consumption of opioids. Electrophysiological studies have shown that remifentanil elicits rapid and prolonged upregulation of $\mathrm{N}$-methyl-D-aspartate receptor (NMDAR) currents, which may contribute to the development of OlH. Glia and other toll-like receptors (TLRs)-expressing cells in the neuroimmune interface have been recognized for their role in the development of neuropathic pain, while compromising the analgesic effects of opioids (9). TLR-mediated signaling and an altered opioidimmune system may be mechanisms to explain $\mathrm{OlH}$, if it truly exists in humans $(9,10)$.

$\mathrm{OlH}$ is generally considered to be a phenomenon associated with the long-term use of opioids, although the condition has been observed even during shortterm administration of these agents under some circumstances in pre-disposed individuals. With chronic use, over time, individuals taking opioids can develop an increasing sensitivity to noxious stimuli, even evolving a painful response to previously non-noxious stimuli. It is differentiated from tolerance, which occurs when a person no longer responds to the drug in the way that person initially responded. Stated another way, with tolerance it takes a higher dose of the drug to achieve the same level of response achieved initially. During chronic opioid treatment, a particular individual's requirement for dose escalation may be due to tolerance (desensitization of antinociceptive mechanisms), opioid-induced hyperalgesia 
(sensitization of pronociceptive mechanisms), or a combination of both.

Research has suggested that several mechanisms might be at play in the development of $\mathrm{OIH}$, including the expression of the transient receptor potential vanilloid type 1 (TRPV1) ion channel and the development of hyperalgesia (11). Recent reports suggest that opioid or TRPV1 receptor agonist exposure has contrasting consequences for anti-nociception, tolerance and dependence. Chronic morphine (and presumably other mu-agonist opioid) exposure modulates TRPV1 activation and induces the antinociception effects of morphine. The regulation of many downstream targets of TRPV1 plays a critical role in this process, including calcitonin gene-related peptide (CGRP) and substance P (SP) (11).

Experimental evidence has investigated the effects of remifentanil, along with ketamine (NMDAR antagonist) and naloxone ( $\mu$-opioid receptor antagonist), on GluN1 mRNA levels and the amount of phosphorylated GluN1 in primary cultures of embryonic rat dorsal horn neurons (DHNs) (12). DHNs were isolated from 18-19-day rat embryos and treated with remifentanil or vehicle for $1 \mathrm{~h}$. GluN1 mRNA and protein levels, determined by real time reverse transcription polymerase chain reaction (RT-PCR) and Western blot, respectively, were significantly and persistently increased by remifentanil exposure compared with the control group $(P<0.05)$. These results may partially account for the mechanism of remifentanil-induced hyperalgesia. This increase was prevented by ketamine (NMDAR antagonist) and naloxone ( $\mu$-opioid receptors antagonist), thus providing a potential therapeutic mechanism for the prevention of opioid-induced hyperalgesia (12).

While Remifentanil and Alfentanil use in experimental circumstances has been associated with likely development of $\mathrm{OIH}$, does this translate in human models of patients exposed to these ultra-rapid opioids in a clinical, surgical setting? The answer remains murky, as noted in one of the largest reviews on the topic conducted to date (13). In a review of twenty-seven studies involving 1,494 patients, patients treated with high intra-operative doses of opioid reported higher postoperative pain intensity than the reference groups at $4 \mathrm{hrs}$, and at $24 \mathrm{hrs}$ on a 100 $\mathrm{cm}$ visual analogue scale. They also showed higher postoperative morphine use after $24 \mathrm{hrs}$. There was no difference in the incidences of nausea, vomiting, and drowsiness. These results were mainly associated with the use of remifentanil. The impact of other opioids is less clear because of limited data (13).

It appears that the intraoperative use of ketamine (NMDAR antagonist) may be useful if administered acutely and concurrently to minimize the development of $\mathrm{OlH}$ in patients undergoing surgery who receive Remifentanil. Seventy-five patients undergoing gynecologic surgery under remifentanil-based anesthesia were assigned to one of the following groups: (1) group RL (remifentanil $0.05 \mu \mathrm{g} / \mathrm{kg} / \mathrm{min}$ ), (2) group $\mathrm{RH}$ (remifentanil $0.3 \mu \mathrm{g} / \mathrm{kg} / \mathrm{min}$ ), or (3) group $\mathrm{KRH}$ (remifentanil $0.3 \mu \mathrm{g} / \mathrm{kg} / \mathrm{min}$ + ketamine $0.5 \mathrm{mg} / \mathrm{kg}$ bolus with $5 \mu \mathrm{g} / \mathrm{kg} / \mathrm{min}$ infusion intraoperatively). Desflurane was administered for maintenance of anesthesia. All parameters related to $\mathrm{OIH}$ and its attenuation induced by ketamine were investigated. Additional analgesic consumption, numerical rating scale scores at 6 and $24 \mathrm{hrs}$, and cumulative fentanyl dose were significantly higher in group $\mathrm{RH}$ than in the other two groups. The value difference of the TouchTest sensory evaluation was significantly higher negative in group $\mathrm{RH}$ than in the other two groups. Remifentanil-induced hyperalgesia was significantly attenuated by intraoperative bolus and infusion of ketamine. Ketamine also decreased tactile sensitization, as measured by Touch-Test sensory evaluation (14). In chronic pain patients chronically consuming opioids, intraoperative ketamine infusion was noted to reduce morphine PCA consumption and sedation in a group of 147 patients undergoing lumbar spinal fusion surgery (15). Studies such as these demonstrate the ability of ketamine administered contemporaneously to ultra-short opioid use to prevent OlH development, but until now nobody has demonstrated, in a clinical setting, the ability of ketamine to treat $\mathrm{OlH}$ once it has developed.

In this edition of Case Reports in Interventional Pain Management, Liang et al describe, for the first time, the use of ketamine infusion used to treat a rapidly evolving condition of probable OlH not during surgery with opioids, but rather in a post-surgical patient requiring escalating and prohibitive doses of opioids to manage postoperative amputation pain (16). The authors detail the story of a 56 year-old man with 
multiple medical co-morbidities who was chronically opioid dependent following multiple spine related surgical interventions who presented for an abovethe-knee amputation related to a diabetic peripheral neuropathy. On the first post-operative day, some 24 hours after undergoing the amputation, his opioid requirements became exponentially higher each hour, with each escalation being associated with escalating pain levels, until a decision was made to eliminate opioids and substitute a ketamine infusion to manage his symptoms. This proved to be successful over several days, illustrating for the first time the use of a "ketamine-rescue" protocol to arrest an evolving $\mathrm{OIH}$ condition in the postoperative period.

While we still have a great deal to learn about $\mathrm{OIH}$, and its clinical presentation in the chronic pain sufferer, as well as what opioids trigger it and in what doses, and who is most likely to be predisposed, this case is an example of using available scientific infor- mation conducted on human (17-19) and in laboratory animals to present a possible strategy, yet unproven, to combat an evolving critical situation in a postoperative patient treated with opioids who actually worsened with each successive opioid dose escalation. While ketamine has not been deemed the most appropriate pharmacological agent for all patients suspected of having $\mathrm{OlH}$, and while the feasibility of using similar NMDAR drugs like Memantine orally in these patients remains to be proven, this case study does demonstrate that $\mathrm{OIH}$ should be suspected when paradoxically pain increases concomitant to increasing opioid administration. While reducing or eliminating opioids would seem to be intuitive, having agents available that can reverse the hyperalgesia while simultaneously treating the painful condition remains a challenge, and doing so after the $\mathrm{OIH}$ has already occurred is a greater challenge still. 


\section{REFERENCES}

1. Manchikanti L, Kaye AM, Knezevic NN, McAnally H, Slavin K,Trescot AM,Blank S, Pampati V, Abdi S, Grider JS, Kaye AD, Manchikanti KN, Cordner H, Gharibo CG, Harned ME, Albers SL, Atluri S, Aydin SM, Bakshi S, Barkin LR, Benyamin, RM, Boswell MV, Buenaventura RM, Calodney AK, Cedeno DL, Datta S, Deer TR, Fellows B, Galan V, Grami V, Hansen H, Helm li S, Justiz R, Koyyalagunta D, Malla Y, Navani A, Nouri KH, Pasupuleti R, Sehgal N, Silverman SM, Simopoulos TT, Singh V, Solanki DR, Staats PS, Vallejo R, Wargo RW, Watanabe A, Hirsch JA. Responsible, safe, and effective prescription of opioids for chronic non-cancer pain: American Society of Interventional Pain Physicians (ASIPP) guidelines. Pain Physician 2017; 20:S3-S92.

2. Knezevic NN, Khan OM, Beiranvand A, Candido KD. Repeated quantitative urine toxicology analysis may improve chronic pain patient compliance with opioid therapy. Pain Physician 2017; 20:S135-S145.

3. Kaye AD, Jones MR, Kaye AM, Ripoll JG, Galan V, Beakley BD, Calixto F, Bolden JL, Urman RD, Manchikanti L Prescription opioid abuse in chronic pain: An updated review of opioid abuse predictors and strategies to curb opioid abuse: Part 1. Pain Physician 2017; 20:S93-S109.

4. Kaye AD, Jones MR, Kaye AM, Ripoll JG, Jones DE, Galan V, Beakley BD, Calixto F, Bolden JL, Urman RD, Manchikanti L Prescription opioid abuse in chronic pain: An updated review of opioid abuse predictors and strategies to curb opioid abuse (Part 2). Pain Physician 2017; 20:S111-S133.

5. Agarin T, Trescot AM, Agarin A, Lesanics D, Decastro C. Reducing opioid analgesic deaths in America: What health providers can do. Pain Physician 2015; 18:E307-E322.

6. Lee M, Silverman S, Hansen H, Patel V, Manchikanti. A comprehensive review of opioid-induced hyperalgesia. Pain Physician 2011; 14:145-161.

7. Schifftner C, Schulteis G, Wallace MS. Effect of intravenous alfentanil on nonpainful thermally induced hyperalgesia in healthy volunteers. J Clin Pharmacol 2017; DOI:10.1002/jcph.911. [Epub ahead of print].

8. Kim SH, Stoicea N, Soghomonyan S, Bergese SD. Intraoperative use of remifentanil and opioid induced hyperalgesia/acute opioid tolerance: Systematic review. Front Pharmacol 2014;
5:108.

9. Shah M, Choi S. Toll-like receptor-dependent negative effects of opioids: A battle between analgesia and hyperalgesia. Front Immunol 2017; 8:642.

10. Plein L, Rittner $\mathrm{H}$. Opioids and the immune system-friend or foe. Br J Pharmacol 2017:10:1111/bph.13750. [Epub ahead of print].

11. Bao Y, Gao Y, Yang L, Kong X, Yu J, Hou W, Hua B. The mechanism of mu-opioid receptor (MOR)-TRPV1 crosstalk in TRPV1 activation involves morphine anti-nociception, tolerance and dependence. Channels (Austin) 2015; 9:235-243.

12. Zhang C, Li SS, Zhao N, Yu C. Phosphorylation of the GluN1 subunit in dorsal horn neurons by remifentanil: A mechanism for opioid-induced hyperalgesia. Genet Mol Res 2015; 14:18461854.

13. Fletcher D, Martinez V. Opioid-induced hyperalgesia in patients after surgery: A systematic review and a meta-analysis. $\mathrm{Br} J \mathrm{An}$ aesth $2014 ; 112: 991-1004$.

14. Choi E, Lee H, Park HS, Lee GY, Kim YJ, Baik HJ. Effect of intraoperative infusion of ketamine on remifentanil-induced hyperalgesia. Korean J Anesthesiol 2015; 68:476-480.

15. Nielsen R, Fomsgaard J, Siegel H, Martusevicius R, Nikolajsen $\mathrm{L}$, Dahl J, Mahiesen O. Intraoperative ketamine reduces immediate postoperative opioid consumption after spinal fusion surgery in chronic pain patients with opioid dependency: A Randomized, blinded trial. Pain 2017; 158:463-470.

16. Liang X, Candido K, Knezevic N. Perioperative ketamine infusion is effective in reversing opioid-induced hyperalgesia. Interventional Pain Management Reports 2017; 1:51-55.

17. Iacobucci GJ, Visnjevac O, Pourafkari L, Nader, ND. Ketamine: An Update on cellular and subcellular mechanisms with implications for clinical practice. Pain Physician 2017; 20:E285-E301.

18. Moyse DW, Kaye AD, Diaz JH, Qadri MY, Lindsay D, Pyati S. Perioperative ketamine administration for thoracotomy pain. Pain Physician 2017; 20:173-184.

19. Mohamed SA, El-Rahman AM, Fares KM. Intrathecal dexmedetomidine, ketamine, and their combination added to bupivacaine for postoperative analgesia in major abdominal cancer surgery. Pain Physician 2016; 19:E829-E839. 